American Journal of Applied Sciences 7 (1): 140-144, 2010

ISSN 1546-9239

(C) 2010 Science Publications

\title{
Comparing Reading Processing Strategies of Second Language Readers
}

\author{
${ }^{1}$ Parilah M. Shah, ${ }^{2}$ Aminuddin Yusof, ${ }^{3}$ Suhana M. Lip, ${ }^{4}$ Nurulhafizah Mahmood, \\ ${ }^{5}$ Yurni Emilia A. Hamid and ${ }^{6}$ Shahirah M. Hashim \\ ${ }^{1}$ Department of Methodology and Educational Practice, Faculty of Education, \\ National University of Malaysia, 43600 UKM Bangi, Selangor, Malaysia \\ ${ }^{2}$ Department of Sports Studies, Faculty of Educational Studies, \\ Putra University of Malaysia, 43400 UPM Serdang, Selangor, Malaysia \\ ${ }^{3}$ Faculty of Education, Selangor International Islamic University College, \\ 43600 Bangi, Selangor, Malaysia \\ ${ }^{4}$ Baitulmal Skill Institute, Taman Maluri, 55100 Kuala Lumpur, Malaysia \\ ${ }^{5}$ Faculty of Major Language Studies, Islamic Science University of Malaysia, Malaysia \\ ${ }^{6}$ MARA University of Technology Malaysia, 32610 Bandar Baru Seri Iskandar, Perak, Malaysia
}

\begin{abstract}
Problem statement: The message that a writer tries to convey in a text would be subjected to several interpretations by readers. Apparently, reading is a complex process of getting input. A wellknown researcher offers two views of reading: (i) reading is a process of decoding written symbols and (ii) reading is a process of reconstructing meaning. It has also been proposed that readers used reading processing strategies in the process of understanding text. Most language educators are not aware of the specific reading strategies that second language readers utilize. Therefore, it is deemed necessary to conduct a study that could explore the specific types of strategies used and to compare the strategies utilized by readers of differing abilities. Approach: A study is conducted to examine the second language readers' use of reading strategies at the Malaysian secondary schools. They read a piece of reading material, and then respond to questionnaires concerning reading strategies such as supervising strategies, support strategies and paraphrase strategies. Results: The findings indicate that there are differences in reading strategies used by second language readers of differing abilities for some of the question items. The results suggest the need to address the incorporation of reading strategy instruction in the language curriculum in order to produce more efficient readers. Conclusion: This investigation is another useful contribution to the applied linguistics research since second language educators would gain better insight into the readers' comprehension process.
\end{abstract}

Key words: Reading processing strategies, second language readers

\section{INTRODUCTION}

Understanding a reading material is a complex and an intriguing process. Nunan (1999) states that reading is a means of obtaining information and making sense of the text; he suggests two views of reading: (i) reading is a process of decoding written symbols, (ii) reading is a process of reconstructing meaning. Related literature indicated that readers spontaneously utilize comprehension or reading strategies in the process of comprehending text (Pritchard, 1990). Previous research also discovered that the use of appropriate strategies could enhance reading comprehension (Olsen and Gee, 1991). Language educators lack the knowledge of what their learners do while attempting to understand reading materials; very often, they are unaware whether or not their students do employ reading comprehension strategies. On the basis of this justification, a study was conducted to investigate the English as a Second Language (ESL) readers' use of reading processing strategies. Distinctively, this investigation sought to ascertain the application of supervising strategies, support strategies and paraphrase strategies and to compare the strategies utilized by second Language (L2) readers of differing abilities Therefore, it endeavors to answer the following Research Questions (RQ): (RQ1) Is there a statistically significant difference between the good and average

Corresponding Author: Parilah M. Shah, Department of Methodology and Educational Practice, Faculty of Education, National University of Malaysia, Malaysia 
readers with respect to the use of the supervising strategies?; (RQ2) Is there a statistically significant difference between the good and average readers with respect to the use of the support strategies? and (RQ3) Is there a statistically significant difference between the good and average readers with respect to the use of the paraphrase strategies?

Related studies of reading processing strategies: The concept of "reading processing strategies "or" reading strategies" refers to plans or methods that can be used or taught to facilitate reading proficiency. Examples of reading/comprehension strategies are inferencing, keyword method, grouping, resourcing, transfer, elaboration, imagery and deduction (Toriyama, 1993). However, not all reading strategies contribute to successful reading comprehension. Padron and Waxman (Padron and Waxman, 1988) categorized reading/comprehension strategies as being negatively or positively related to students' reading achievement. Writing down every word, reading as fast as one can, saying every word over and over again are some examples cited as negatively related, while summarizing in writing, self-generated questions, imaging are instances presented as positively related to readers' achievement. According to Olsen and Gee (1991), literature has suggested that comprehension strategies could improve reading comprehension. It is the adoption of the appropriate learning sets and strategies that learners can become successful even when the talents they bring to the task are minimal (Carroll, 1977). Pritchard (1990) stresses that comprehension is affected by the interaction of cultural content schemata and reading processing strategies. This is especially relevant to second language learning and reading situation.

Most of previous second language studies compare and contrast reading/comprehension strategies within particular second languages, that is intralingually; while others compare and contrasts strategies across native and target languages, that is, interlingually (Bernhardt, 1991). The number of studies conducted in the area of reading/comprehension strategies in the second language can be said to be increasing. However, this is still not as abundant when compared to studies done in English as the first language. The following presents some of the studies conducted in this area using second language readers as the subjects.

Arden-Close (1993) conducted a study that examined the similarities and differences between three nonnative-speaker university students of English in the use of strategies to infer the meanings of unknown words found in their reading of English. The three readers were categorized as a 'good' reader, an 'average' reader and a 'poor' reader. The students' answers to a series of six readings were obtained. The information about readers' strategies was not only derived from these answers but also from a series of questionnaires. Some significant findings were that all the readers including the weakest made use of their world knowledge; only the good reader made use of the context beyond a paragraph; the good student used a wider range of strategies and all the students showed strength when responding to their own specialized subject, in this instance chemistry.

Investigators such as Carrell et al. (1993) compared the native and nonnative speakers' performance on the same task and across languages using a fixed-ratio random selection cloze tests. Close performance is viewed as a window on native and nonnative readers' strategies. The subjects were university students out of which sixty were Chinese speakers and twenty-eight were English speakers. The Chinese students were treated with cloze tests in Chinese and English while the English speakers performed on the English cloze test. One of the findings was that the English and Chinese speakers performed in a similar manner on the English cloze and that both groups appeared to use the same strategies. Another significant finding was that the readers performed differently in different languages (Chinese and English), that is, the Chinese readers' responses were not similar on the Chinese and English closes.

A study conducted by Knight et al. (1985) explored the differences in the type and frequency of cognitive reading/comprehension strategies used by ESL and monolingual students of a school by carrying out audiotaped individual interviews. The subjects consisted of twenty-three ESL students who were native speakers of Spanish and fifteen monolingual students who were native speakers of English. A passage from the Ekwall reading inventory manual was selected as the reading material, which the students read and stopped at intervals to give a response on the reading comprehension strategies they were using. The findings indicated that the English speakers used concentrating, noting details and self-generated questions more often than the ESL students. In fact, they utilized two times as many strategies as the ESL students. The investigators considered this a possible factor for the poor performance of ESL students on the Texas Assessment of Basic Skill. The conclusion of the investigators for these circumstances was that the ESL students might have been placed to English reading too early that they did not have much time to develop the strategies when reading texts in Spanish. It seemed to 
the researchers that the ESL students' inclination was on their decoding skills than on their strategies.

\section{MATERIALS AND METHODS}

This survey research examined the reading processing strategies used by second language students in Malaysian schools. Four secondary schools were selected; the schools were located in the Klang Valley area in Malaysia. The respondents were $32(n=32)$ Form four Malay students who studied English as a second language in their schools, in which reading was one of the activities that they would be engaged in. All of them were 16 years old and there were 18 good readers and 14 average readers who participated in this research.

The gathering of the data was rather tedious because the data were obtained from one student at a time. Each subject was required to be involved in a reading task. Each of the students read a piece of reading material and then responded to the questionnaires concerning reading/comprehension strategies. After the subjects had read the text for at least three times, the research assistants asked them to retell the content (story) of the text, which was done in the English language and also the Malay language, to obtain the extent of students' comprehension of the reading material. Then, the research assistants asked the subjects about the reading strategies they used by going over the question items one at a time.

Pritchard's (1990) Inventory of Reading Processing Strategies was adapted and utilized to collect the data. There were twenty-eight items from the instrument that were analyzed. These items pertained to the three categories of reading processing strategies, namely supervising strategies, support strategies and paraphrase strategies. The learners were required to choose one from three choices-(1) always, (2) sometimes, (3) never-from each question item. The form four ESL learners also answered questions with respect to background such as age, sex, ethnicity, hometown, school and length of exposure to English. An SPSS program was used to process the data. T-test was conducted to find whether there are significant differences between the good and average language learners with respect to the reading processing strategies used. A p-value of $<0.05$ was used to determine the level of significance.

\section{RESULTS}

This investigation has answered three research questions. The answers to the first Research Question (RQ1) "Is there a statistically significant difference between the good and average readers with respect to the use of the supervising strategies?" are discussed in terms of the aspects such as "states success in understanding a portion of the text," "states failure in understanding a portion of the text," "recognizes loss of concentration," "adjusts reading rate in order to increase comprehension," "formulates a question," "makes a prediction about the meaning of a word or about text content," "refers to lexical items that impede comprehension," "confirm/disconfirms an inference," "refers to the previous paragraph," and "responds affectively to text content."

The results in Table 1 indicated that majority of the items showed significant differences between the good and average students with respect to the use of supervising strategies. The significant items are "states success in understanding a portion of the text" $($ good $=1.22$; average $=1.86)$, "states failure in understanding a portion of the text" $(\operatorname{good}=2.72$; average $=1.86$ ), "recognizes loss of concentration" (good $=2.56$; average $=2.00)$, "formulates a question" $($ good $=1.22 ;$ average $=2.64)$, "refers to lexical items that impede comprehension" $(\operatorname{good}=1.33$; average $=2.29$ ), "refers to the previous paragraph" (good $=1.72$; average $=2.29)$ and "responds affectively to text content" (good $=1.56$; average $=2.14)$. The insignificant items (indicated by an*) are "adjusts reading rate in order to increase comprehension" $($ good $=1.67 ;$ average $=1.71)$, "makes a prediction about the meaning of a word or about text content" $($ good $=1.56 ;$ average $=1.57)$ and "confirm/disconfirms an inference" $($ good $=1.89$; average $=1.86)$.

The presentation to the answers for the second Research Question (RQ2) "Is there a statistically significant difference between the good and average readers with respect to the use of the support strategies?" are in terms of the aspects such as "skips unknown words," "expresses the need of a dictionary," "skims reading material for a general understanding," "scans reading material for a specific word or phrase," and "visualizes."

The findings in Table 2 also showed that majority of the items indicated significant differences between the good and average students with respect to the use of support strategies. The items that indicated significant differences are "skips unknown words" (good = 1.61; average $=2.36$ ), "expresses the need of a dictionary" $($ good $=2.11$; average $=1.71)$, "skims reading material for a general understanding" $(\operatorname{good}=1.28$; average $=2.14)$ and "visualizes" $(\operatorname{good}=1.17$; average $=1.64)$. However, there is no significant difference (indicated by an *) between the two groups with regards to "scans reading material for a specific word or phrase" (good $=2.00$; average $=2.14)$. 
Am. J. Applied Sci., 7 (1): 140-144, 2010

Table 1: Supervising strategies

\begin{tabular}{|c|c|c|c|}
\hline Question items & Means of good & Means of average & p-value \\
\hline Supervising strategies. The reader: & Readers & Readers & \\
\hline States success in understanding a portion of the text & 1.22 & 1.86 & 0.000 \\
\hline States failure in understanding a portion of the text & 2.72 & 1.86 & 0.000 \\
\hline Recognizes loss of concentration & 2.56 & 2.00 & 0.048 \\
\hline Adjusts reading rate in order to increase comprehension & 1.67 & 1.71 & $0.863^{*}$ \\
\hline Formulates a question & 1.22 & 2.64 & 0.000 \\
\hline Makes a prediction about the meaning of a word or about text content & 1.56 & 1.57 & $0.952 *$ \\
\hline Refers to lexical items that impede comprehension & 1.33 & 2.29 & 0.001 \\
\hline Confirms/disconfirms an inference & 1.89 & 1.86 & $0.908^{*}$ \\
\hline Refers to previous paragraph & 1.72 & 2.29 & 0.034 \\
\hline Responds affectively to text content & 1.56 & 2.14 & 0.022 \\
\hline
\end{tabular}

Table 2: Support strategies

\begin{tabular}{|c|c|c|c|}
\hline Question items & $\begin{array}{l}\text { Means } \\
\text { of good }\end{array}$ & $\begin{array}{l}\text { Means } \\
\text { of average }\end{array}$ & p-value \\
\hline Support strategies. The reader: & Readers & Readers & \\
\hline Skips unknown words & 1.61 & 2.36 & 0.002 \\
\hline Expresses the need for a dictionary & 2.11 & 1.71 & 0.041 \\
\hline $\begin{array}{l}\text { Skims reading material } \\
\text { for a general understanding }\end{array}$ & 1.28 & 2.14 & 0.000 \\
\hline $\begin{array}{l}\text { Scans reading material for } \\
\text { a specific word or phrase }\end{array}$ & 2.00 & 2.14 & $0.621 *$ \\
\hline Visualizes & 1.17 & 1.64 & 0.031 \\
\hline
\end{tabular}

Table 3: Paraphrase strategies

\begin{tabular}{|c|c|c|c|}
\hline Question items & $\begin{array}{l}\text { Means } \\
\text { of good }\end{array}$ & $\begin{array}{l}\text { Means } \\
\text { of average }\end{array}$ & p-value \\
\hline Paraphrase strategies. The reader: & Readers & Readers & \\
\hline $\begin{array}{l}\text { Uses cognates between } \mathrm{L} 1 \text { and } \mathrm{L} 2 \\
\text { to comprehend }\end{array}$ & 2.17 & 1.43 & 0.007 \\
\hline Breaks lexical items into parts & 2.22 & 2.29 & $0.817 *$ \\
\hline Paraphrases & 1.67 & 2.64 & 0.000 \\
\hline $\begin{array}{l}\text { Translates a word or a phrase } \\
\text { into the L1 }\end{array}$ & 2.17 & 1.50 & 0.011 \\
\hline $\begin{array}{l}\text { Extrapolates from information } \\
\text { presented in the text }\end{array}$ & 1.50 & 2.21 & 0.001 \\
\hline $\begin{array}{l}\text { Speculates beyond the information } \\
\text { presented in the text }\end{array}$ & 2.11 & 2.07 & $0.858^{*}$ \\
\hline
\end{tabular}

The discussion to the answers for the third research question "Is there a statistically significant difference between the good and average readers with respect to the use of the paraphrase strategies?" are in terms of the aspects such as "uses cognates between first Language (L1) and second Language (L2) to comprehend," "breaks lexical items into parts," "paraphrases," "translates a word or a phrase into the L1," extrapolates from the information presented in the text," and "speculates beyond the information presented in the text."

As can be seen in Table 3, most of the paraphrase strategies used between the good and average readers showed significant differences. The strategies that showed significant differences are "uses cognates between L1 and L2 to comprehend" $(\operatorname{good}=2.71$; average $=1.43), \quad$ "paraphrases" $\quad(\operatorname{good}=1.67$; average $=2.64$ ), "translates a word or a phrase into the L1" $($ good $=2.17 ;$ average $=1.50)$ and extrapolates from the information presented in the text" $(\operatorname{good}=1.50$; average $=2.21$ ). Nevertheless, there are no significant differences (indicated by an *) between the two groups with respect to "breaks lexical items into parts," (good $=2.22$; average $=2.29)$ and "speculates beyond the information presented in the text" $($ good $=2.11 ;$ average $=2.07)$.

\section{DISCUSSION}

The good and average second language readers showed significant differences in majority of the reading processing strategies employed. The good second language readers tended to use more reading strategies and the frequency of use is greater than that used by the average second language readers. The good second language readers were also more inclined to use more of the better reading strategies in comparison to the average readers. It is due to the frequent use of better strategies that the good readers were able to show good attainment and obtain outstanding achievement in the English language compared to the average second language readers who were somewhat incompetent in the second language.

\section{CONCLUSION}

The findings showed differences in the reading processing strategies used by the good and average students. The good students preferred to use better strategies than the average learners. The average readers should be taught how to use better strategies so that their reading comprehension can be enhanced. The results contribute positively to the field of applied linguistics since educators would gain more insight of students' reading/comprehension activity. Just as it proves to be beneficial to the educators, it would benefit the learners even more, as appropriate methodology and techniques would be employed and emphasized so as to help them to excel in their second language reading performance. This research suggests that students should be trained to use more effective comprehension 
strategies; this means that the relevant educational bodies would need to incorporate a more systematic reading/comprehension strategy instruction into the English language curriculum content.

\section{REFERENCES}

Arden-Close, C., 1993. NNS reader's strategies for inferring the meanings of unknown words. Reading Foreign Language, 9: 867-893. http://nflrc.hawaii.edu/rfl/PastIssues/rfl92ardenclos e.pdf

Bernhardt, E.B., 1991. Reading Development in a Second Language: Theoretical, Empirical and Classroom Perspectives. Ablex Publishing Corporation, New Jersey, ISBN: 0-89391-675-7, pp: 12.

Carrell, P.L., J.G. Carson and D. Zhe, 1993. First and second language reading strategies: Evidence from cloze. Reading Foreign Language, 10: 953-965. http://nflrc.hawaii.edu/rfl/PastIssues/rfl101 carrell.p df

Carroll, J.B., 1977. Characteristics of Successful Second Language Learners. In: Viewpoints on English as a Second Language, Burt, M., H. Dulay and M. Finnochiaro (Eds.). Regents, New York, ISBN: 0-88345-298-7, pp: 1-7.
Knight, S.L., Y.N. Padron and H.C. Waxman, 1985. The cognitive reading strategies of ESL students. TESOL Q., 19: 789-792.

Olsen, M. and T. Gee, 1991. Content reading instruction in the primary grades: Perceptions and strategies. Read. Teacher, 45: 298-307.

Padron, Y.N. and H.C. Waxman, 1988. The effect of ESL students' perceptions of their cognitive reading strategies on reading achievement. TESOL Q., 22: 146-150.

Pritchard, R., 1990. The effects of cultural schemata on reading processing strategies. Read. Res. Q., 25: 273-295.

Toriyama, K., 1993. The study on reading strategy of students learning Japanese as a second language. Proceeding of the Midwest Conference on Asian Affairs, (AA'93), Cleveland, Ohio, p. 5. http://www.eric.ed.gov/ERICDocs/data/ericdocs $2 \mathrm{~s}$ q1/content_storage_01/00000196/80/13/24/2f.pdf

Nunan, D. 1999. Second language teaching and learning. Newbury House Teacher Development, Boston, ISBN: 0-83840-838-9, pp: 5-7. 